\title{
Are schools safer for children than public places?
}

\author{
A K Maitra, G Sweeney
}

\begin{abstract}
Objective-To investigate the frequency and severity of accidents to children in schools.

Methods-Retrospective analysis of accidents occurring in school over a six month period and resulting in attendance at an accident and emergency department. Comparison was made with accidents occurring in public places,

Results-During the study period there were 127 school and 251 public place accidents causing fractures or dislocations requiring hospital treatment in 3-16 year old children; $22 \cdot 4 \%(127 / 567)$ of all injuries at school resulted in fractures or dislocations, as opposed to $20 \cdot 8 \%(251 / 1197)$ of those sustained in public places.

Conclusions-Injuries at school are a cause for concern as they occur in a supervised environment and this should be the target of accident prevention measures. (F Accid Emerg Med 1996;13:196-197)
\end{abstract}

Key terms: school; accident; prevention; fractures/ dislocations

Accidental injury to children is a common occurrence; however, accidents in schools have not been as widely investigated as those occurring at home or in road traffic accidents. In 1969, Dale et al ${ }^{1}$ raised questions concerning safety at school. Since then several studies ${ }^{2-4}$ have described the nature and causes of school accidents in children, have found that fractures and dislocations occur frequently, and have suggested preventive measures.

We retrospectively investigated the frequency and severity of accidents to children in schools where the environment is assumed to be safe and activities supervised compared to those sustained in public places, where children are not generally supervised so as to further highlight the importance of dealing with these serious injuries in schools.

\section{Results}

During a period of six months, 567 school and 1197 public place accident victims attended the accident and emergency (A\&E) department: $127(22 \cdot 4 \%)$ school and $251(20 \cdot 9 \%)$ public place accidents caused fractures or dislocation.

The mean and median age (years) of the children was 11.2 and 12 (school) and 10.4 and 11 (public place), respectively. Older children (11-16 years) were more involved in school injuries (figure). Among girls, the 11-16 year olds sustained more injuries in school $(67 \cdot 4 \%)$ than in public places $(33 \cdot 7 \%)$.
SITE OF INJURY

Details of the sites of injury are shown in the table.

SEVERITY OF INJURY

The mean injury severity scores (ISS) were $5 \cdot 3$ for school and 6.7 for public place injuries. The difference was not statistically significant.

DISPOSAL

Only a small percentage of school $(3.9 \%)$ and public place $(6 \cdot 4 \%)$ injuries were discharged to the general practitioner. The majority required treatment in $\mathrm{A} \& \mathrm{E}$, fracture, and other specialist clinics. Four children $(3 \cdot 2 \%)$ with school injuries and $27(10 \cdot 8 \%)$ with public place injuries required hospital admission.

\section{Discussion}

Studies from Sweden ${ }^{4} 5$ have reported that $22-24 \%$ of school accidents result in fractures/ dislocations. Our study confirmed these findings and also indicates that school injuries occur with similar frequency to injuries in public places, where the environment is very varied and generally unsupervised. This is a matter of great concern because one would expect school to be a much safer place. It is, however, known (unpublished data) that one third of all school injuries occur where the activities are supervised.

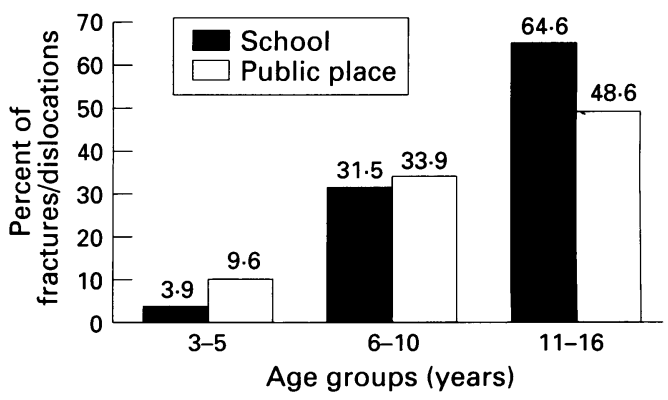

Distribution of age groups in fractures/dislocations occurring in school $(n=127)$ and public place $(n=251)$

Description of anatomical site of fractures or dislocation, $n$ (\%)

\begin{tabular}{lcc}
\hline Site of injury & $\begin{array}{l}\text { School } \\
(n=127)\end{array}$ & $\begin{array}{l}\text { Public place } \\
(n=251)\end{array}$ \\
\hline Head/neck & $4(3 \cdot 2)$ & $4(1 \cdot 6)$ \\
Arm/shoulder & $7(5 \cdot 5)$ & $21(8 \cdot 4)$ \\
Forearm/elbow & $10(7 \cdot 9)$ & $28(11 \cdot 2)$ \\
Wrist & $36(28 \cdot 3)$ & $99(39 \cdot 4)$ \\
Hand & $12(9 \cdot 5)$ & $19(7 \cdot 6)$ \\
Digit & $36(28 \cdot 3)^{\star}$ & $41(16 \cdot 3)$ \\
Trunk & 0 & 0 \\
Lower limb (above ankle) & $2(1 \cdot 6)$ & $9(3 \cdot 6)$ \\
Ankle and foot (and toes) & $20(15 \cdot 7)$ & $30(11 \cdot 9)$ \\
\hline
\end{tabular}

$\star \mathrm{P}=0.02$. 
Fractures and dislocations may require a prolonged period of treatment, can cause morbidity in children due to growth plate involvement, and result in loss of school time for educational, recreational, and sporting activities.

Measures are required to prevent or substantially reduce these serious school injuries. A target reduction of $10-20 \%$ of these fractures/dislocations might be achieved at individual school level by closely monitoring the causes of these injuries and increasing awareness. By involving everyone, including the children, sensible preventive measures could be formulated, without the need for extra resources.

Practical preventive measures may include targeting specific age and sex groups (older girls), when, during school hours, the majority of accidents happen (during lessons, breaktime, and so on), geographical areas of school frequently involved in accidents (gym, playground), surface (for example, wood, concrete), and specific activities (for example, football, netball).

We thank $\mathrm{Mr} M$ Choyce for helpful suggestions and Miss C Richards for typing the manuscript.

1 Dale M, Smith M, Weil J, Parrish H. Are schools safe? Analysis of 409 student accidents in elementary schools. Clin Pediatr 1969;8:294-6.

2 Maddocks GB, Sibert JR, Brown BM. A four week study of accidents to children in South Glamorgan. Public Health 1978;92:171-6.

3 Jacobsson B, Bek-Jensen H, Janssion B. (1986). One year's incidence of school accidents and their severity in a Swedish municipality. Scand $\mathcal{f}$ Primary Health Care Swedish municip

4 Schelp L, Ekman R, Fahl I. School accidents during a three school year period in a Swedish municipality. Public Health 1991;105:113-20.

\title{
9th Annual Trauma Anaesthesia and Critical Care Symposium, May 16-17, 1996
}

\author{
Sponsored by International Trauma Anaesthesia and Critical \\ Care Society
}

\author{
Royal College of Surgeons of England \\ Lincoln's Inn Fields \\ London WC2A 3PN
}

For further information contact: Ms Sally Jenner, Association of Anaesthetists of Great Britain and Ireland, 9 Bedford Square, London WC1B 3RA. (Tel 0171631 1650.) 